\title{
Parametric Studies of Advanced Turboprops
}

J.G. Maser and D.G. Fertis

The University of Akron

Akron, Ohio

and

R.A. Aiello and C.C. Chamis

Lewis Research Center

Cleveland, Ohio

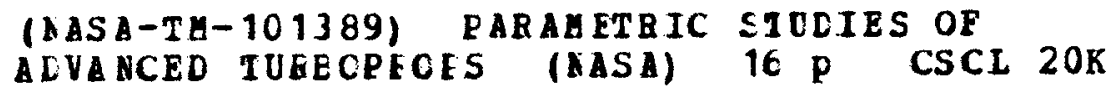

Prepared for the

29th Structures, Structural Dynamics and Materials Conference cosponsored by the AIAA, ASME, ASCE, AHS, and ACS

Williamsburg, Virginia, April 18-20, 1988 


\title{
PARAMETRIC STUDIES OF ADVANCED TURBOPROPS
}

\author{
J.G. Maser and D.G. Fertis \\ The University of Akron \\ Akron, Ohio 44325 \\ and \\ R.A. Aiello and C.C. Chamis \\ National Aeronautics and Space Administration \\ Lewis Research Center \\ Cleveland, Ohio 44135
}

SUMMARY

The effects of geometric variables (sweep and twist) on the structural performance of advanced turboprops are investigated. The investigation is limited to aerodynamically efficient turboprops using an acceptable design configuration as a baseline. The baseline configuration is modified using a seven by seven array of independently varying sweep and twist parameters while maintaining acceptable aerodynamic efficiency. The turboprop structural performance is evaluated in terms of critical speeds, tip displacements, and vibration frequencies where geometric nonlinearities are included. The results obtained are presented in such a manner as to highlight the effects of sweep and twist on the structural performance of aerodynamically efficient turboprop configurations.

\section{INTRODUCTION}

The potential for high propulsive efficiency in the Mach 0.7 to 0.8 speed range has renewed the interest in propeller propulsion systems in recent years. Improved multi-bladed propellers, termed advanced turboprops, have the potential for reduced fuel consumption while maintaining the performance levels of modern turbofans. Advanced turboprop concepts feature thin, swept and twisted propeller blades often with complex structural properties. Such turboprop blades are twisted in order to obtain an efficient angle of attack at all points along the radius of the blade. Furthermore, the sweep angle produces a significant reduction in noise and, therefore, is a desirable design feature.

Traditionally, development of feasible advanced turboprop blades has involved a process of repeating trial configurations. Specifically, a swept and twisted turboprop blade would be developed based on advantageous aerodynamic characteristics (including the high efficiency and low noise) and then it would be considered for structural analysis. However, blades of this type (thin, highly swept and twisted) exhibit a complex state of structural response under a centrifugal force field. Often, as a result, blades which were aerodynamically desirable were not structuraliy feasible. This conflict necessitated the development of new blade configurations with the previous structural limitations kept in mind. However, a relatively few number of blade configurations (less than 8) have been developed and investigated, and it is not known exactly how the structural limitations of each configuration may be related. 
The objective of this paper is to describe a study which was conducted in order to investigate the effects of sweep and twist upon the structural response of turboprop configurations with acceptable (within a range) aerodynamic efficiency under a centrifugal force field (ref. I) as will be described later. Specifically, an existing, representative advanced turboprop, named SR5, was used as a model on which variations of sweep and twist were made. An available proprietary computer code for aerodynamic propeller performance analysis was used to establish an array of turboprop blade configurations with acceptable aerodynamic efficiency. The array contains blades with seven different sweeps and seven different twists for a total of 49 combinations. This paper includes summaries of analyses and significant results. Extensive discussions and details are provided in reference 1.

\section{TURBOPROP GEOMETRY AND ANALYSIS}

\section{Advanced Turboprop Geometry and Definitions}

A representative turboprop stage and propeller blade (turboprop) with the Cartesian coordinate axes are shown in figure 1 . The sweep angle of a turboprop is defined as the angle measured from the plane of rotation to the tangent of the 50 percent chord line (fig. 2(a)). This definition may be used to specify the sweep at any radius, $r$, where radius corresponds to the $x$-axis and is defined as the distance from the center of rotation on the line formed by the intersection of the plane of rotation and the plane of forward velocity of the propeller. The characteristic sweep angle assigned to a given turboprop blade is defined as the sweep angle at $3 / 4$ of the radius from the center of rotation to the tip of the blade, $3 / 4 \mathrm{R}$. The blade airfoil section is shown in figure $2(b)$.

The twist angle of a propeller blade is defined as the angle measured from the plane of rotation to the chord line in a plane normal to the pitch change axis, where this axis corresponds to the radial line and $x$-axis (fig. 3 ). As with sweep, the twist angle definition may be used to specify twist at any radius, $r$, but the characteristic twist angle assigned to a given turboprop blade is defined as the twist at $3 / 4 \mathrm{R}$.

\section{Representative SR5 Turboprop Description and Analysis Model}

The finite-element model of the aerodynamically scaled SR5 turboprop blade used as the baseline for the parametric studies, is shown in figure 4. The blade is solid titanium and is approximately 10 in. long with a tip chord of 2 in., and a maximum chord at the hump of 3.8 in. Thickness varies from 1 in. at midchord at the root to $0.040 \mathrm{in}$. at midchord at the tip. The leading edge thickness varies from $0.180 \mathrm{in}$. at the root to $0.022 \mathrm{in}$. at the tip. The trailing edge thickness varies from $0.077 \mathrm{in}$. at the root to 0.016 in. at the tip. The SR5 has a characteristic twist angle of $66.0^{\circ}$ and a characteristic sweep angle of $30.7^{\circ}$ (tip sweep of $63^{\circ}$ ). The total weight of the SR5 is $0.719 \mathrm{lb}$. This SR5 blade was designed to evaluate aerodynamic efficiency in wind tunnel tests.

The coordinate system, for SR5 and subsequent turboprop configuration variations, is Cartesian and defined as shown in figures 1 and 4 . The $x$ origin is at the center of the hub and the $y$ origin is at the midchord of the shank. 
The finite-element analysis model ( $f i g .4$ ) consists of 423 grid points and 744 CTRIA3 elements (refs. 2 to 4 ). For convenience, the midchord is defined to be the sixth node in from either the leading or trailing edge on any given chord line. All chords are defined in the $y-z$ plane. The sweep at any radius was based on the tangent to the line connecting the midchords. This midchord definition is not exactly the 50 percent chordline; however, it was very close and used consistently in all the turboprop configurations of the parametric studies. This finite-element model was used to evaluate the structural performance of the propeller (displacements, frequencies, critical speeds) including the effects of geometric nonlinearity. The validity for using this approach and comparisons with other sources are given in reference 5 .

A graphical approach was employed to vary the distributed sweep in a relatively uniform manner. Specifically, the SR5 midchord line was plotted from existing data for the baseline model, and six new midchord lines were constructed in order to retain the characteristics of the SR5 while successively decreasing the sweep. Sweep increases were not considered because previous investigation indicated the SR5's high degree of sweep resulted in significant differences in tip displacements at relatively low rotational speeds (ref. 5 ). Such displacements are considered to be indicative of the onset of structural instability and, as a result, the SR5 was regarded as an upper limit to sweep. The distributed twist was varied by using a similar approach.

\section{Turboprop Aerodynamic Performance}

A proprietary computer code based on strip analysis (available at NASA Lewis Research Center) was used to evaluate the performance of the turboprops (propellers) for a given set of conditions. The output of this code includes values such as drag-to-lift ratios, sectional efficiencies, sectional losses, and sectional Mach numbers, all given at Gauss stations. In addition, the thrust and apparent efficiency of the propeller are provided.

The apparent efficiency is based on the apparent thrust of a propeller operating in a region of reduced velocity due to the presence of a body behind it. In brief, efficiency is defined as

$$
\eta=\frac{\text { power output }}{\text { power input }}=\frac{(\text { thrust)(velocity) }}{2 \pi n(\text { torque })}=\frac{T V}{2 \pi n Q}
$$

where: $T=$ thrust; $V=$ forward speed of airplane; $n=$ rotational speed; $Q=$ torque.

The elemental thrust is the force produced by the blade element along the line of flight and is determined from elemental lift forces minus elemental drag forces taken along this line. The elemental torque is the force produced by the blade element resisting rotation multiplied by the radial distance to the center of rotation, and is determined from the elemental lift plus elemental drag taken along the plane of rotation.

Since aerodynamic performance was evaluated only as a simplified means of establishing acceptable ranges of aerodynamic efficiency of specific propeller configurations, detailed theory is beyond the scope of this paper. However, more detailed theory may be found in references 6 to 8 . The array summarizing 
the parametric studies performed is described in table 1 . The input data is summarized in table 2 .

\title{
RESULTS AND DISCUSSION
}

\author{
Aerodynamic Performance
}

The aerodynamic performance of each turboprop blade was primarily evaluated as a simplified means of establishing acceptable ranges of aerodynamic efficiency to the range of sweep and twist to be investigated. Therefore, the criterion used to judge the aerodynamic performance of a given propeller blade was apparent efficiency. The basis used for establishing ranges on apparent efficiency is the data from a high speed propeller performance Lewis in-house wind tunnel study shown in figure 5 (ref. 9). As can be seen, at any Mach number, design efficiencies vary by a relatively small amount (on the order of 3 percent). As a result, it was established that relative drops in apparent efficiency of 3 to 4 percent, from any encountered maximum, would make a configuration aerodynamically unacceptable. Therefore, based on this criterion, the 49 turboprop configurations defined in table 1 were established as configurations with acceptable aerodynamic efficiency.

In addition to establishing limits to the configuration matrix, this analysis provided some meaningful information concerning the effects of sweep and twist variation upon the apparent efficiencies of a propeller. It is noted that investigation of design speed variations for each specific configuration was beyond the scope of this study and, as a result, all of the configurations were evaluated, aerodynamically, at the same rotational speed with accompanying changes in air speed and relative Mach number. Both of these changes were included in the efficiency calculations.

The effects of sweep variations on apparent efficiencies are shown in figure 6 for lines of constant twist. Figure 7 shows the effects of twist variations on apparent efficiencies for lines of constant sweep. Note that only the turboprop 49 configurations considered aerodynamically acceptable are shown. The blade configurations considered unacceptable had apparent efficiencies of 78 percent or less.

From figures 6 and 7 , it is generally observed that the apparent efficiencies are more sensitive to twist variations. Specifically, for lines of constant sweep, the efficiencies pass through a pronounced maximum as twist increases. The maximum generally occurs in a twist region of $67^{\circ}$ to $70^{\circ}$. On the other hand, for lines of constant twist, the efficiencies are not as smooth with increasing sweep. In particular, for the higher twisted configurations, efficiencies increase and then level off with increasing sweep. For the lower twisted configurations, efficiencies increase steadily with increasing sweep and just begin to level off at the highest sweep considered. Therefore, increases in sweep affect efficiencies more for lower twisted configurations than for higher twisted configurations. As an aside, it can be pointed out that, for the aerodynamic analysis, the sweep and twist angles are defined at Gauss stations. Thus, the manner in which sweep and twist are varied along the radius of the blade would have significant effects on the results; even if the characteristic sweep and twist values remain the same. 


\section{Critical Speeds}

The critical speed referred to, presently and in future context, is the rotational speed (rpm) at which the geometric nonlinear solution no longer converges for that particular blade configuration because diagonal elements in the global stiffness matrix become zero. At this point, tensile buckling would occur as described in reference 10 where the effects of composite materials are also discussed. Each configuration was evaluated in load increments of $1000 \mathrm{rpm}$ until the critical speed was found. Generally, the number of iterations required for convergence range from 3 to 18 .

Figure 8 shows critical speeds as a function of sweep for lines of constant twist. These results are not intuitively obvious since the curves do not exhibit relatively smooth transitions. The curves reflect, in part, the complex interaction effects of propeller geometry that influence its nonlinear behavior. These curves indicate the following general trends: (1) the critical speed decreases as sweep increases, and (2) the critical speed increases as twist increases. The highest values for critical speed occurred at low sweeps and high twists, while the lowest values occurred at high sweeps and low twists.

Tip Displacements

Tip displacements are defined with respect to the midchord of the blade tip and are taken at the last rpm at which the nonlinear solution converged (critical speed - $1000 \mathrm{rpm}$ ). Three types of displacements are considered (fig. 1): y-tip deflection, z-tip deflection, and tip-chord rotation. The $y$-tip deflection is defined as the deflection in the plane of the forward velocity of the propeller ( $x-y$ plane by current coordinate system). The effects of sweep for constant twist angles are shown in figure 9 . The z-tip deflection is defined as the deflections in the plane of rotation ( $x-z$ plane by current coordinate system). The effects of sweep for constant twist angles are shown in figure 10. Lastly, the tip-chord rotation is defined as the change in the blade tip-chord twist angle in a plane normal to the pitch change axis ( $y-z$ plane by current coordinate system). The effects of sweep for constant twist angle are shown in figure 11 .

The significant observation from the results in figures 9 to 11 , is that the structural behavior of swept, twisted turboprops is very complex and requires equally complex structural analyses to be evaluated. A consequence of this observation is that scaling of experimental data will generally require considerable judgment and care.

\section{Vibration Frequencies}

The vibration frequencies in the design speed range are important in stability and life assessment of the blade. In design practice, these are generally evaluated using the interference of vibration frequencies with rotor excitation orders (such as one per revolution (IP), two per revolution (2P), etc.). Figure 12 illustrates the effects of varying sweep with constant Twist $A\left(73^{\circ}\right)$ on a frequency versus rotor speed (Campbell) diagram where the critical speeds are also shown. The frequencies increase as the critical speed is 
approached; however, these increases are very slight. Furthermore, for each mode, as sweep increases the frequencies generally decrease, the exception being Sweep $E\left(26^{\circ}\right)$ in the third mode which has the highest frequency for that mode.

\section{SUMMARY OF RESULTS}

The summary of results and conclusions of a parametric study to investigate the structural performance of advanced turboprops are as follows:

1. Critical speeds (as defined previously), for constant twists, decrease as sweep increases and, for constant sweeps, increase as twist increases. The highest values of critical speed occurred for low sweep, high twist configurations while lowest values occurred for high sweep, low twist configurations.

2. The y-tip displacements only indicate a straightening of sweep for high sweep, high twist blade configurations.

3. Z-tip deflections (magnitude), for constant twists, decrease as sweep increases and, for constant sweeps, decrease as twist increases. The largest $z$-tip deflections occurred for low sweep, low twist configurations while smaller z-tip deflections occurred for high sweep, high twist configurations.

4. The tip-chord rotations indicate that turboprop blades with low twist pass from being more twisted to highly untwisted as sweep increases, while blades with high twist become more twisted as sweep increases. Tip-chord rotations for blades with low sweep become slightly more twisted as twist increases while blades with high sweep have rotations that pass distinctly from being untwisted to being more twisted as twist increases.

5. Large sweep variations have more diverse overall effects on critical speeds and displacements than do large twist variation.

6. Critical speeds are lower in configurations where tip-chord rotations are significant (either more twist or untwist) and higher when rotations are small.

7. For blade configurations with high sweep, high twist, displacements are dominated by tip-chord rotations. For blade configurations with low sweep, low twist, displacements are dominated by z-tip deflections.

8. Vibration frequencies at 0 rpm, constant twist decrease with increasing sweep for the first four modes. Similarly, vibration frequencies for low sweep configurations at $0 \mathrm{rpm}$, decrease with increasing twist, but only for first and second modes. For third and fourth modes vibration frequencies increase with increasing twist for low sweep configurations. For high sweep configurations, frequencies increase with increasing twist for the first four modes. 


\section{REFERENCES}

1. Maser, J.G., "A Parametric Study of Highly Swept Advanced Turboprops", Proposed NASA Contractor Report.

2. McCormick, C.W., ed., MSC/NASTRAN User's Manual, MacNeal-Schwendler Corp., Los Angeles, CA, 1982.

3. Joseph, J.A., ed., MSC/NASTRAN Application Manual, MacNeal-Schwendler Corp., Los Angeles, CA, 1981.

4. MacNeil, R.H., "The NASTRAN Theoretical Manual," NASA SP-221(01), 1972.

5. Aiello, R.A. and Chamis, C.C., "Large Displacements and Stability Analys is of Nonlinear Propeller Structures," NASA TM-82850, 1982.

6. Goldstein, S., "On the Vortex Theory of Screw Propellers, "Proceedings of the Royal Society of London, Vol. 123A, No. 792, Apr. 1929, pp. 440-465.

7. Theodorsen, T., Theory of Propellers, McGraw-Hi11, New York, 1948.

8. Dommasch, D.O., Sherby, S.S., and Connolly, T.F., Airplane Aerodynamics, 4 th ed., Pitman, New York, 1967.

9. Mitchell, G.A., "Lifting Line Strip Analys is Propeller Performance Summary," unpublished research data, NASA Lewis Research Center, Cleveland, $\mathrm{OH}, 1981$.

10. Chamis, C.C. and Aiello, R.A., "Tensile Buckling of Advanced Turboprops," Journal of Aircraft, Vol. 20, No. 11, Nov. 1983, pp. 907-912.

TABLE 1. - RANGE OF SWEEP AND TWIST VARIATIONS

(a) Twist and sweep labels and corresponding angles

\begin{tabular}{|c|c|c|}
\hline $\begin{array}{c}\text { Increasing } \\
\text { sweep }\end{array}$ & \multicolumn{2}{|c|}{ Sweep } \\
\cline { 2 - 3 } & Labe1 & $\begin{array}{c}\text { Angle, } \\
\text { deg }\end{array}$ \\
\hline \multirow{4}{*}{} & A & 14 \\
& B & 16 \\
& C & 20 \\
& D & 23 \\
& E & 26 \\
& F & 29 \\
& G & 31 \\
\hline
\end{tabular}

\begin{tabular}{|c|c|c|}
\hline $\begin{array}{c}\text { Increasing } \\
\text { twist }\end{array}$ & \multicolumn{2}{|c|}{ Twist } \\
\cline { 2 - 3 } & Label & $\begin{array}{c}\text { Angle, } \\
\text { deg }\end{array}$ \\
\hline \multirow{4}{*}{,} & A & 73 \\
& B & 71 \\
& C & 69 \\
& D & 68 \\
& E & 66 \\
& F & 64 \\
& $G$ & 62 \\
\hline
\end{tabular}

(b) 49 combinations for blade configuration matrix

\begin{tabular}{|c|ccccccc|}
\hline $\begin{array}{c}\text { Increasing } \\
\text { twist }\end{array}$ & \multicolumn{7}{|c|}{ Increasing } \\
\cline { 2 - 5 } & & sweep \\
& $A A$ & $B A$ & $C A$ & $D A$ & $E A$ & $F A$ & $G A$ \\
& $A B$ & $B B$ & $C B$ & $D B$ & $E B$ & $F B$ & $G B$ \\
& $A C$ & $B C$ & $C C$ & $D C$ & $E C$ & $F C$ & $G C$ \\
& $A D$ & $B D$ & $C D$ & $D D$ & $E D$ & $F D$ & $G D$ \\
& $A E$ & $B E$ & $C E$ & $D E$ & $E E$ & $F E$ & $G E$ \\
& $A F$ & $B F$ & $C F$ & $D F$ & $E F$ & $F F$ & $G F$ \\
& $A G$ & $B G$ & $C G$ & $D G$ & $E G$ & $F G$ & $G G$ \\
& & &
\end{tabular}


TABLE II. - AERODYNAMIC PROPELLER CHARACTERISTICS

[Number of b]ades a 10; b] ade diameter $=24.1$ in.; spinner cutoff point $=0.212 \mathrm{r} / \mathrm{R}$; shaft horsepower $=104.8$; propeller rotational speed a $5709 \mathrm{rpm}$; altitude $=35000 \mathrm{ft}$; true airspeed $=461.2 \mathrm{kn}$ (Mach 0.79 ); type of airfoil a NACA series 16 compressible.]

(a) Aerodynamic characteristics independent of blade radial distance

\begin{tabular}{|c|c|c|c|c|c|c|c|c|c|c|}
\hline $\begin{array}{l}\text { Gauss station } \\
\text { Thickness/chord } \\
\text { Chord/diameter } \\
\text { Design } 1 \text { ife coefficient } \\
\text { Velocity ratio }\end{array}$ & $\begin{array}{l}0.9902 \\
.018 \\
.1079 \\
.207 \\
1.036\end{array}$ & $\begin{array}{l}0.9489 \\
.018 \\
.1248 \\
.221 \\
1.025\end{array}$ & $\begin{array}{l}0.8787 \\
.021 \\
.1326 \\
.234 \\
1.005\end{array}$ & $\begin{array}{l}0.7856 \\
.024 \\
.1454 \\
.235 \\
.983\end{array}$ & $\begin{array}{l}0.6779 \\
.031 \\
.1562 \\
.213 \\
.960\end{array}$ & $\begin{array}{l}0.5652 \\
.039 \\
.1602 \\
.180 \\
.940\end{array}$ & $\begin{array}{l}0.4575 \\
.051 \\
.1550 \\
.100 \\
.894\end{array}$ & $\begin{array}{l}0.3644 \\
.068 \\
.1506 \\
.060 \\
.850\end{array}$ & $\begin{array}{l}0.2942 \\
.104 \\
.1466 \\
.020 \\
.815\end{array}$ & $\begin{array}{l}0.2529 \\
.175 \\
.1452 \\
.005 \\
.0800\end{array}$ \\
\hline
\end{tabular}

(b) Aerodynamic characteristics dependent on radial distance (values correspond to Gauss stations)

\begin{tabular}{|c|c|c|c|c|c|c|c|c|c|c|}
\hline Twist & \multicolumn{10}{|c|}{ The seven twist configurations at the Gauss stations } \\
\hline $\begin{array}{l}A \\
B \\
C \\
D \\
E \\
F \\
G\end{array}$ & $\begin{array}{r}-6.57 \\
-7.49 \\
-8.29 \\
-9.18 \\
-9.39 \\
-10.68 \\
-11.32\end{array}$ & $\begin{array}{l}-5.31 \\
-6.05 \\
-6.73 \\
-7.48 \\
-8.14 \\
-8.75 \\
-9.29\end{array}$ & $\begin{array}{l}-2.83 \\
-3.21 \\
-3.62 \\
-4.09 \\
-4.42 \\
-4.84 \\
-5.13\end{array}$ & $\begin{array}{r}-0.73 \\
-.82 \\
-.90 \\
-1.02 \\
-1.14 \\
-1.24 \\
-1.33\end{array}$ & $\begin{array}{l}1.53 \\
1.76 \\
1.98 \\
2.19 \\
2.44 \\
2.66 \\
2.91\end{array}$ & $\begin{array}{l}4.05 \\
4.68 \\
5.39 \\
5.97 \\
6.66 \\
7.31 \\
8.01\end{array}$ & $\begin{array}{r}6.96 \\
8.12 \\
9.30 \\
10.44 \\
11.64 \\
12.88 \\
14.16\end{array}$ & $\begin{array}{r}8.57 \\
9.95 \\
11.40 \\
12.82 \\
14.40 \\
15.91 \\
17.56\end{array}$ & $\begin{array}{r}9.08 \\
10.63 \\
12.19 \\
13.71 \\
15.35 \\
17.03 \\
18.73\end{array}$ & $\begin{array}{r}9.64 \\
11.24 \\
12.92 \\
14.56 \\
16.25 \\
18.04 \\
19.91\end{array}$ \\
\hline Sweep & \multicolumn{10}{|c|}{ The seven sweep configurations at the Gauss stations } \\
\hline $\begin{array}{l}A \\
B \\
C \\
D \\
E \\
F \\
G\end{array}$ & $\begin{array}{l}29.73 \\
31.30 \\
37.09 \\
42.55 \\
46.94 \\
53.91 \\
62.44\end{array}$ & $\begin{array}{l}24.80 \\
28.90 \\
36.10 \\
41.67 \\
46.10 \\
51.83 \\
58.39\end{array}$ & $\begin{array}{l}18.21 \\
25.97 \\
27.43 \\
36.61 \\
41.89 \\
44.97 \\
48.49\end{array}$ & $\begin{array}{l}13.71 \\
18.11 \\
22.49 \\
27.34 \\
31.13 \\
33.43 \\
34.22\end{array}$ & $\begin{array}{r}8.42 \\
11.26 \\
13.71 \\
15.38 \\
18.52 \\
20.20 \\
23.37\end{array}$ & $\begin{array}{r}4.12 \\
7.13 \\
9.37 \\
11.42 \\
11.70 \\
12.84 \\
13.93\end{array}$ & $\begin{array}{l}2.18 \\
2.75 \\
3.26 \\
3.72 \\
3.55 \\
3.38 \\
-.46\end{array}$ & -16.96 & -21.31 & $\begin{array}{c}-29.77 \\
1\end{array}$ \\
\hline
\end{tabular}
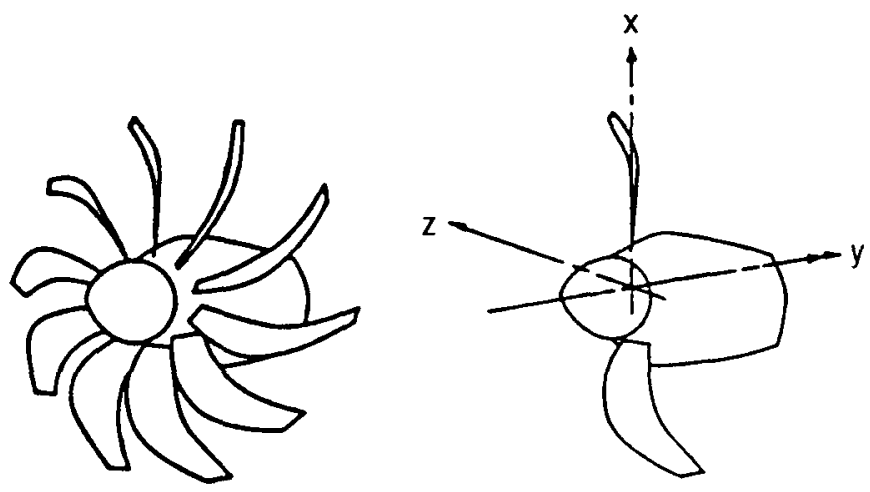

(a) STAGE.

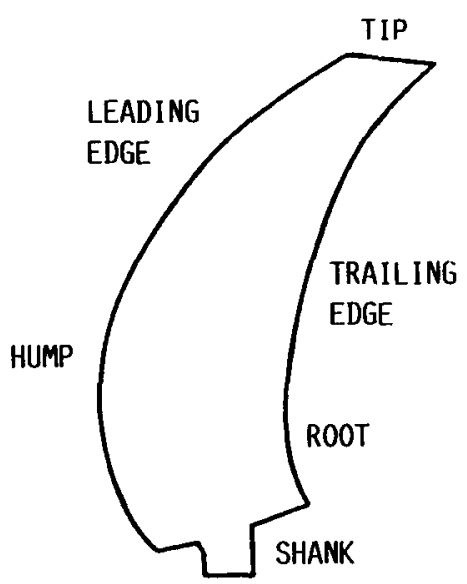

(b) PROPELLER BLADE (TURBOPROP).

FIGURE 1. - REPRESENTATIVE TURBOPROP STAGE AND PROPELLER (TURBOPROP). 


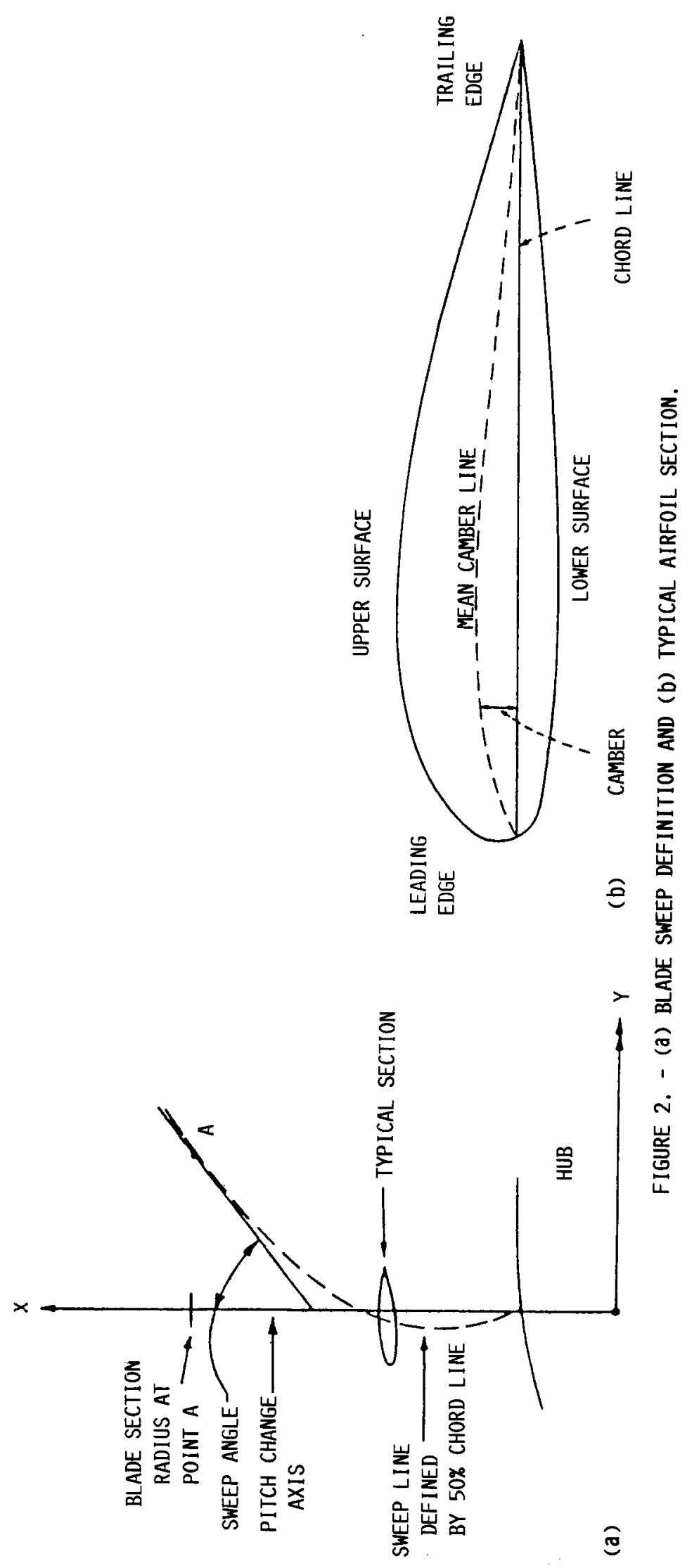




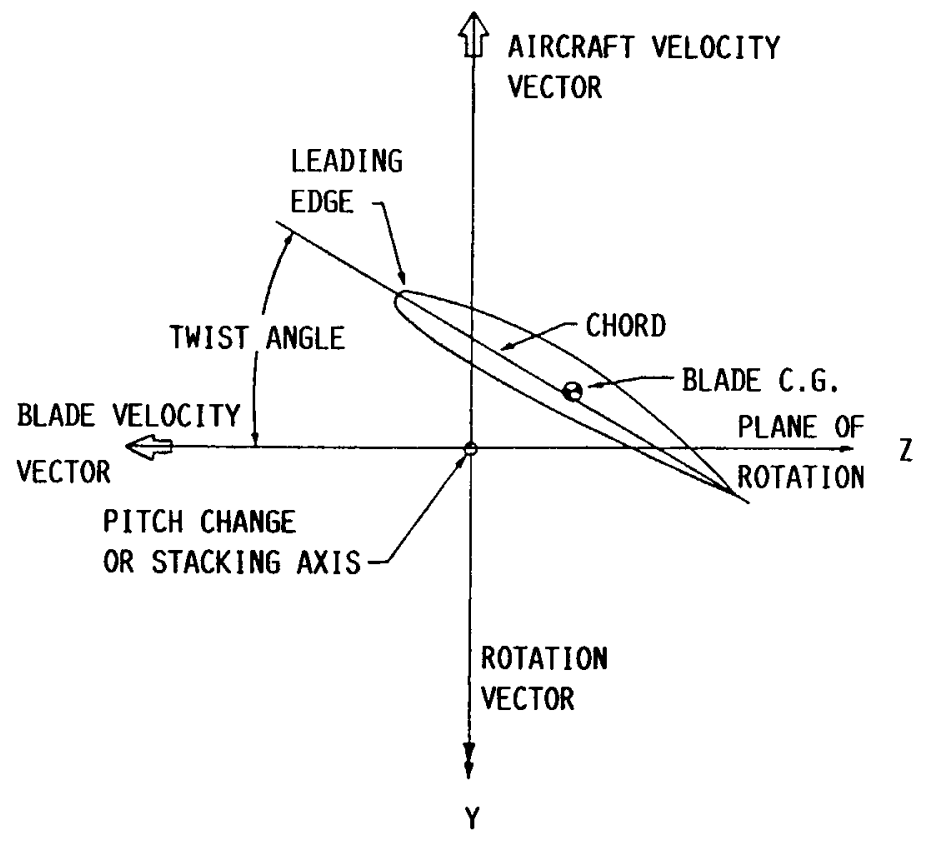

TIP TO HUB VIEW

FIGURE 3. - BLADE TWIST DEFINITION.

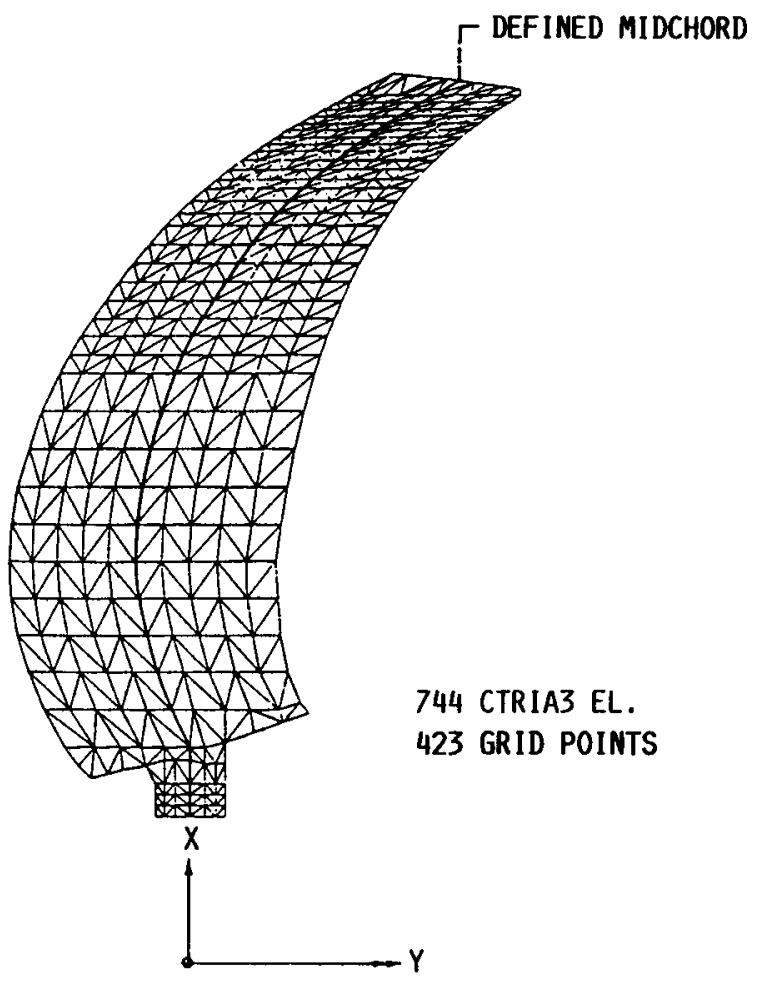

FIGURE 4. - TURBOPROP FINITE ELEMENT MODEL. 


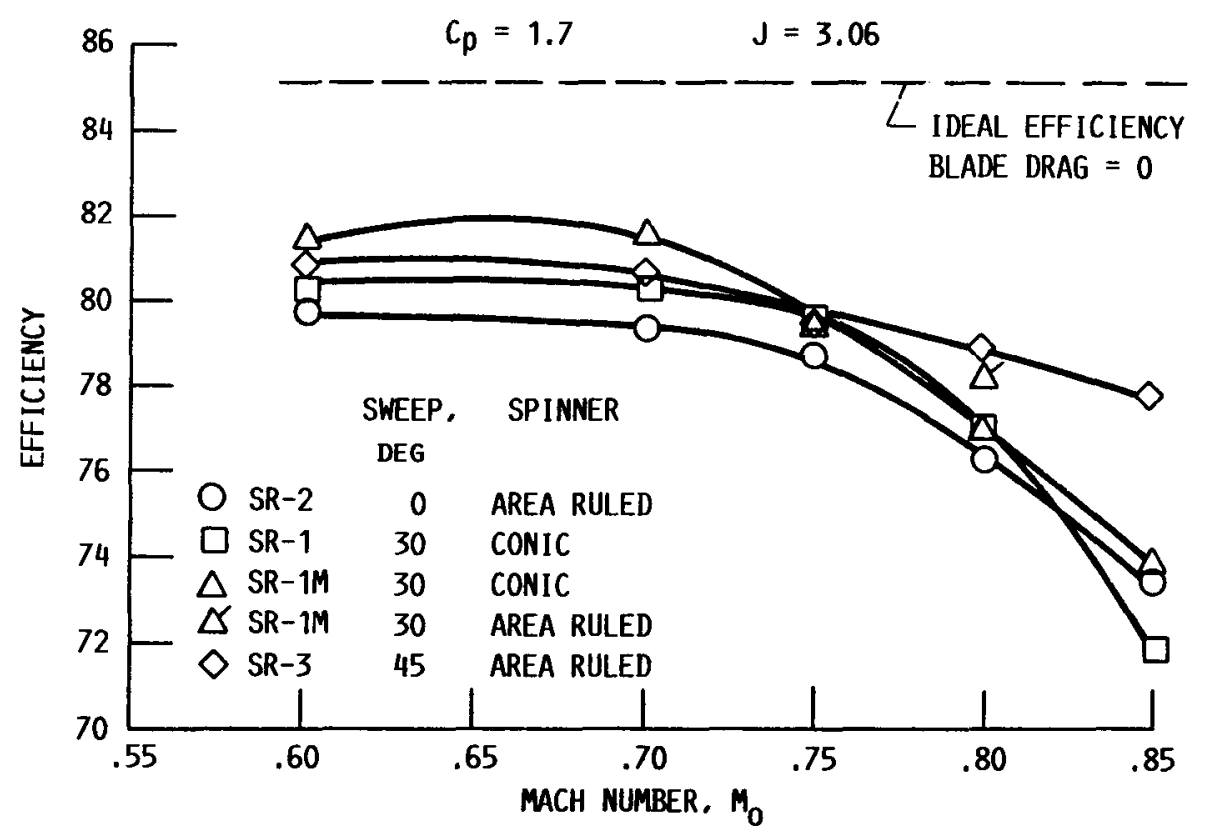

FIGURE 5. - HIGH SPEED PROPELLER PERFORMANCE SUMMARY BASED ON STRIP ANALYSIS.

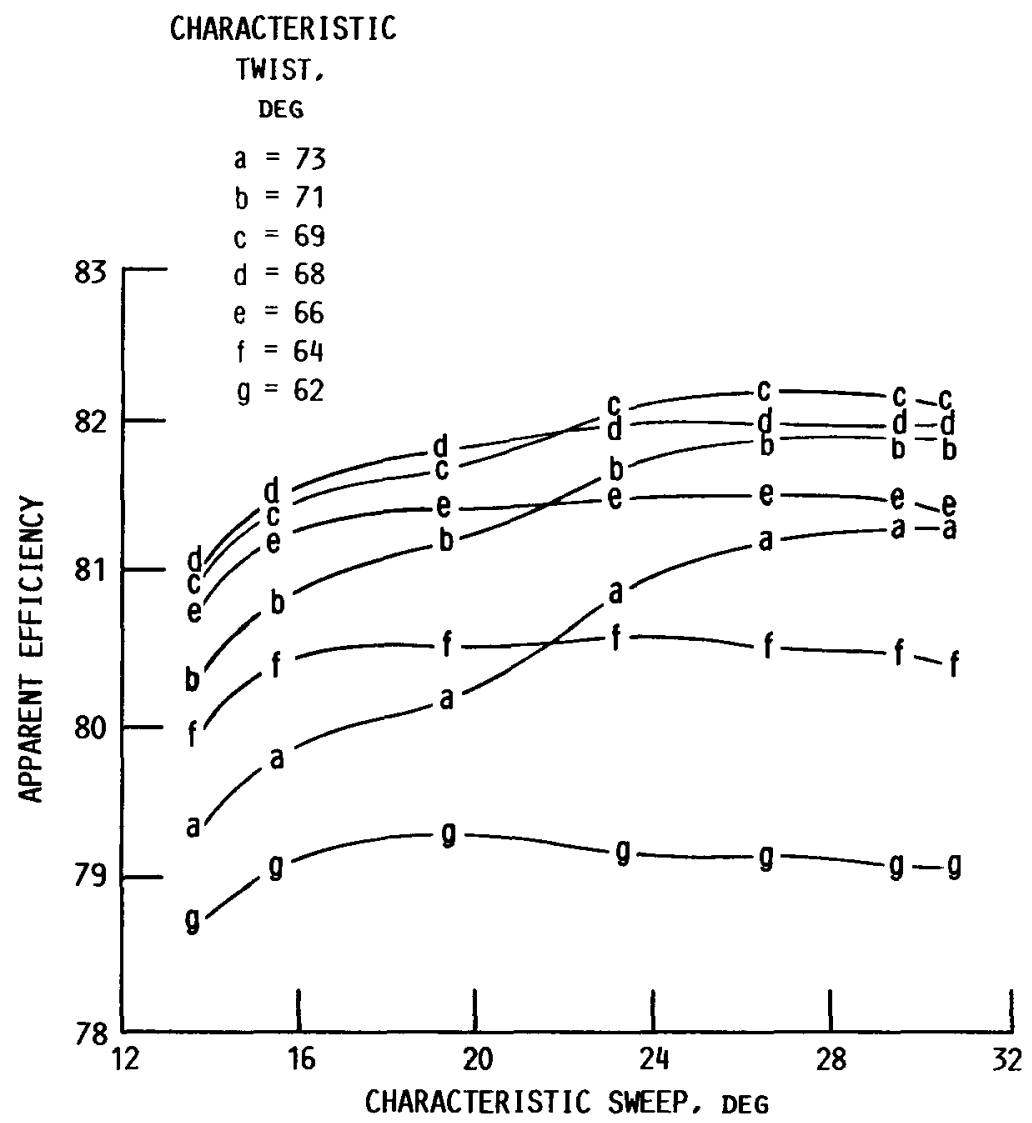

FIGURE 6. - EFFECT OF SWEEP ON APPARENT EFFICIENCY FOR LINES OF CONSTANT TWIST. 


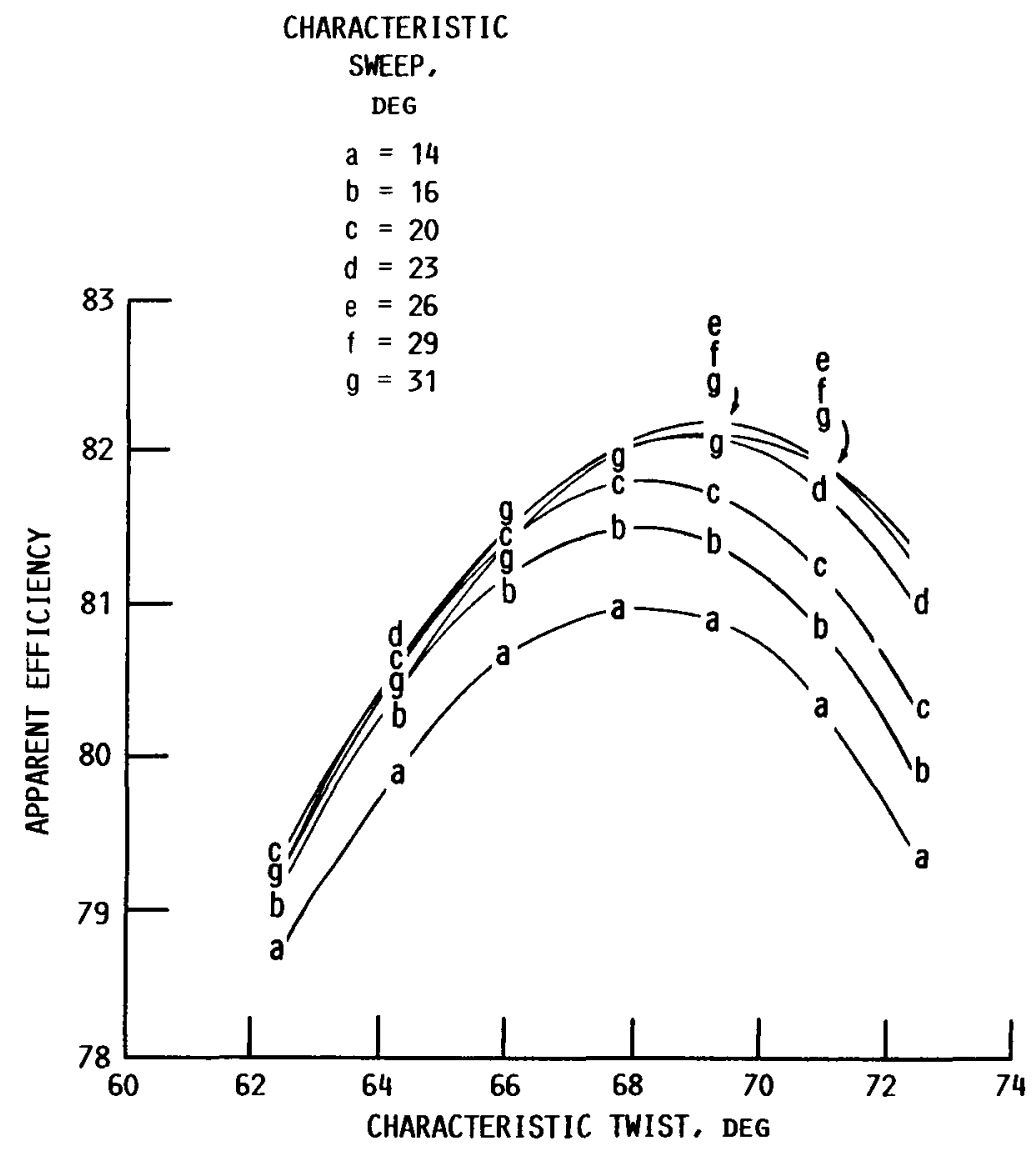

FIGURE 7. - EFFECT OF TWIST ON APPARENT EFFICIENCY FOR LINES OF CONSTANT SWEEP.



FIGURE 8. - EFFECT OF CHARACTERISTIC SWEEP ON CRITICAL SPEED FOR LINES OF CONSTANT CHARACTERISTIC TWIST. 


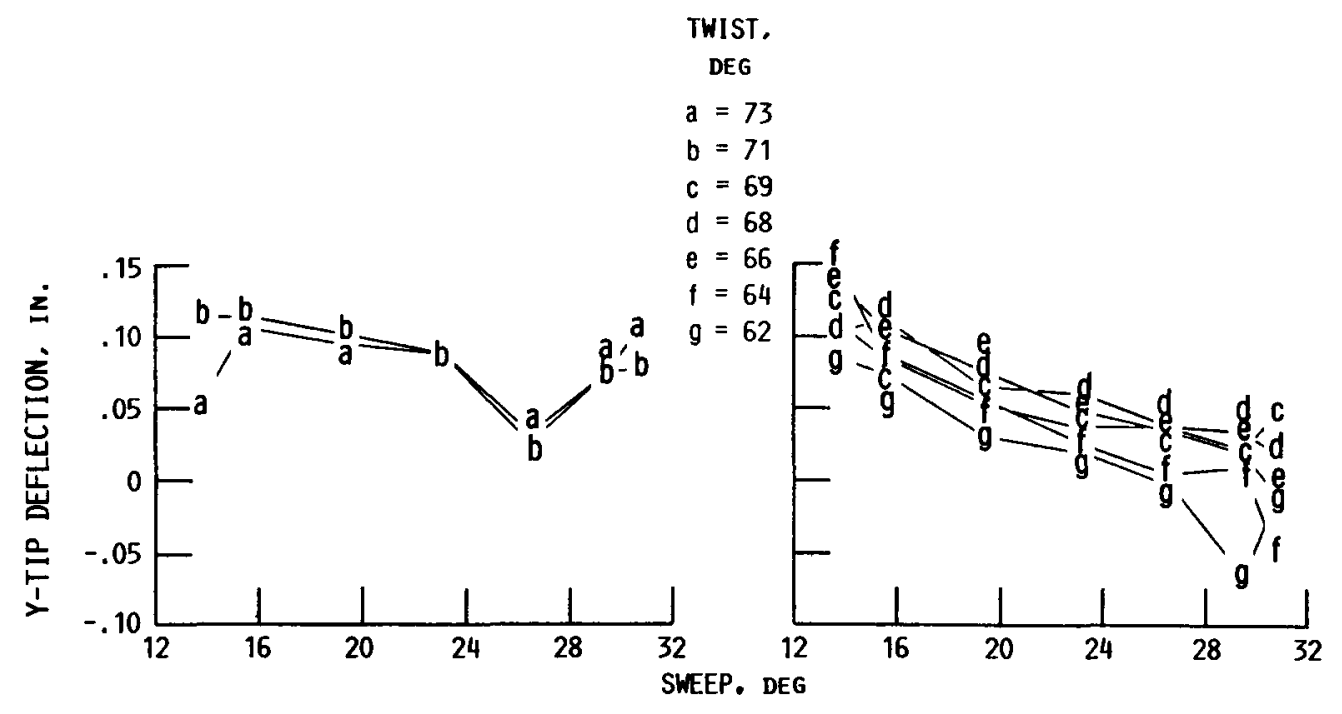

FIGURE 9. - EFFECT OF CHARACTERISTIC SPEEP ON Y-TIP DEFLECTION FOR LINES OF CONSTANT CHARACTERISTIC TWIST.

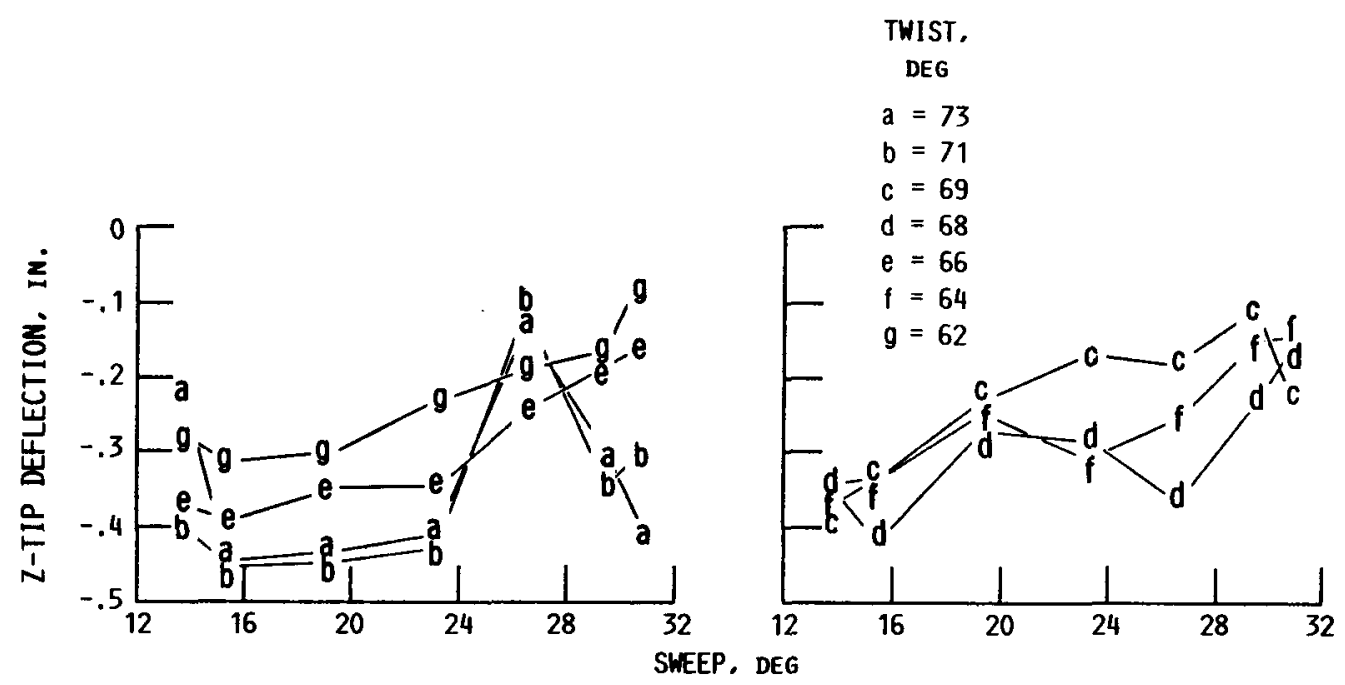

FIGURE 10. - EFFECT OF CHARACTERISTIC SWEEP ON Z-TIP DEFLECTION FOR LINES OF CONSTANT CHARACTERISTIC TWIST.

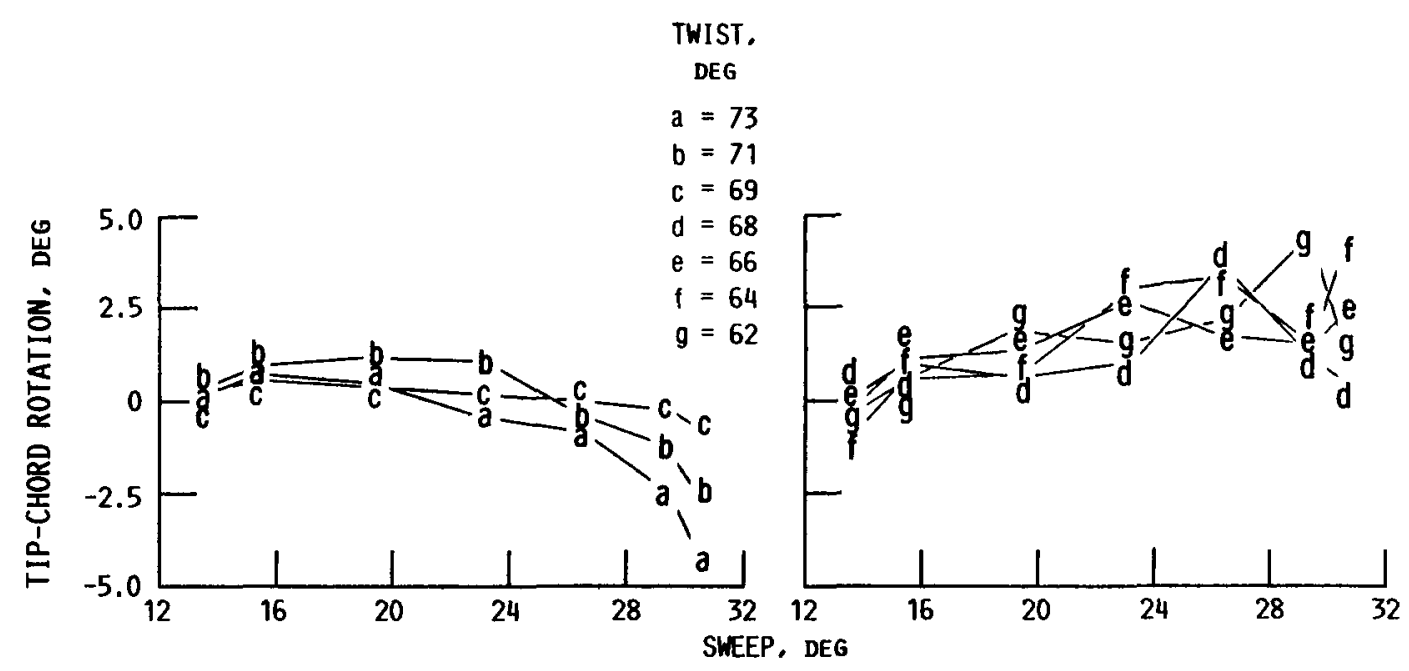

FIGURE 11. - EFFECT OF CHARACTERISTIC SWEEP ON TIP-CHORD ROTATION FOR LINES OF CONSTANT CHARACTERISTIC TWIST. 


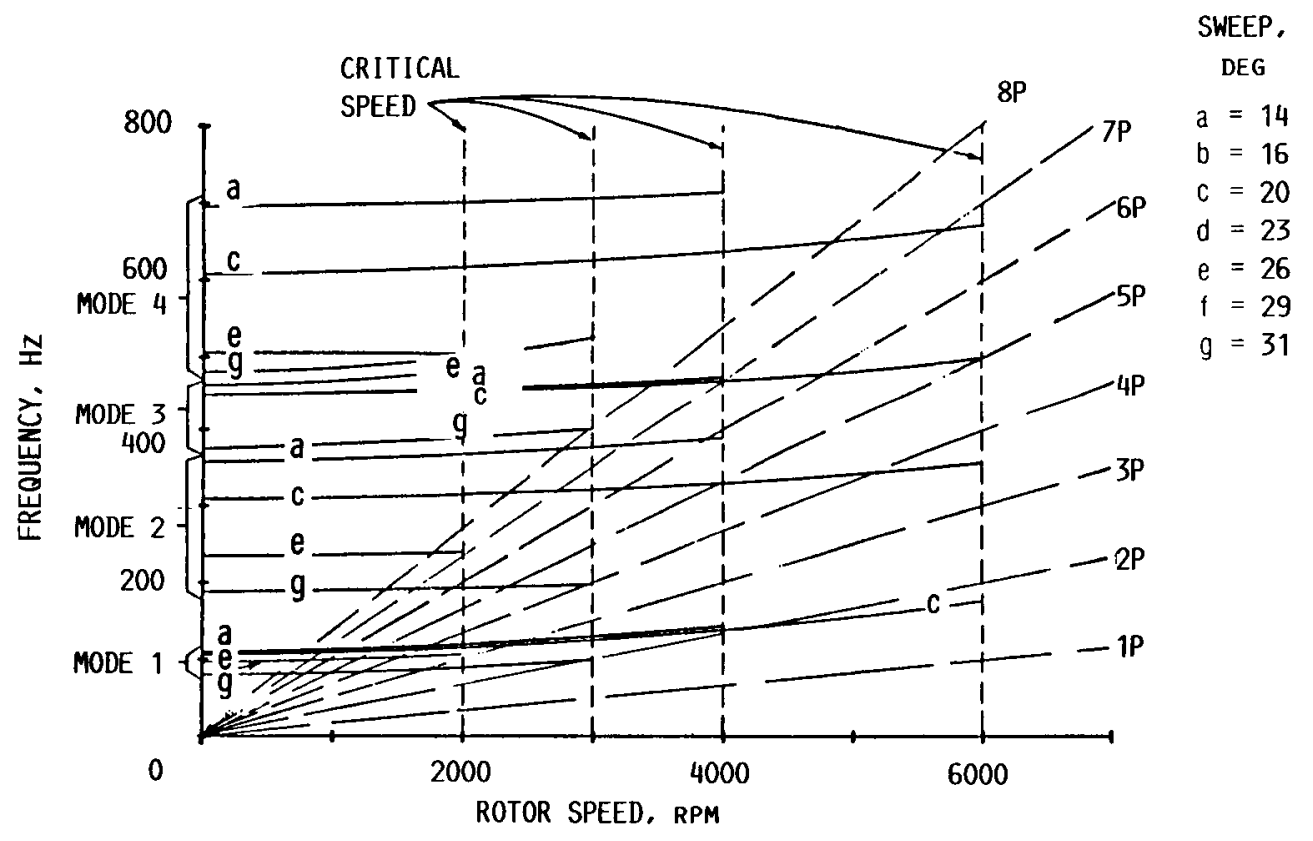

FIGURE 12. - CAMPBELL DIAGRAM WITH ROTOR EXCITATIONS FOR DIFFERENT CHARACTERISTIC SWEEP ANGLES, CONSTANT CHARACTERISTIC TWIST $A\left(73^{\circ}\right)$. 


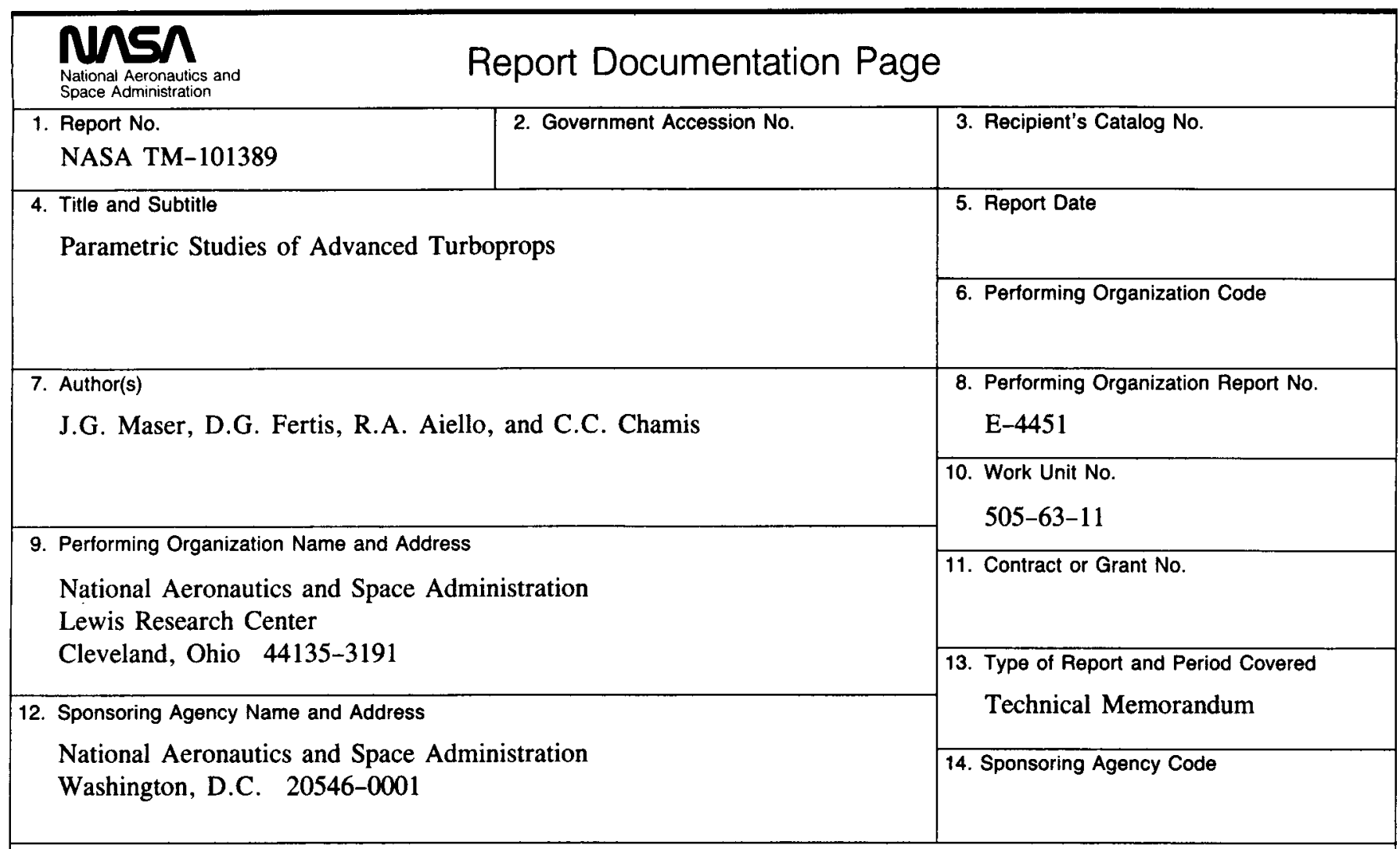

15. Supplementary Notes

Prepared for the 29th Structures, Structural Dynamics and Materials Conference, cosponsored by the AIAA, ASME, ASCE, AHS, and ACS, Williamsburg, Virginia, April 18-20, 1988. J.G. Maser and D.G. Fertis, The University of Akron, Akron, Ohio 44325; R.A. Aiello and C.C. Chamis, NASA Lewis Research Center.

\section{Abstract}

The effects of geometric variables (sweep and twist) on the structural performance of advanced turboprops are investigated. The investigation is limited to aerodynamically efficient turboprops using an acceptable design configuration as a baseline. The baseline configuration is modified using a seven by seven array of independently varying sweep and twist parameters while maintaining acceptable aerodynamic efficiency. The turboprop structural performance is evaluated in terms of critical speeds, tip displacements, and vibration frequencies where geometric nonlinearities are included: The results obtained are presented in such a manner as to highlight the effects of sweep and twist on the structural performance of aerodynamically efficient turboprop configurations.

17. Key Words (Suggested by Author(s))

Sweep; Twist; Frequencies; Tip displacements; Critical speeds; Finite element; Large displacements; Geometric nonlinearities; Campbell diagrams; Aerodynamic efficiency
18. Distribution Statement

Unclassified-Unlimited

Subject Category 39

19. Security Classif. (of this report)

Unclassified

20. Security Classif. (of this page)

Unclassified

21. No of pages

22. Price*

16

A03 